\title{
Large-scale distribution analysis of Antarctic echinoids using ecological niche modelling
}

\author{
Benjamin Pierrat ${ }^{1, *}$, Thomas Saucède ${ }^{1}$, Rémi Laffont ${ }^{1}$, Chantal De Ridder ${ }^{2}$, \\ Alain Festeau ${ }^{1}$, Bruno David ${ }^{1}$ \\ ${ }^{1}$ Biogéosciences, UMR CNRS 6282, Université de Bourgogne, 21000 Dijon, France \\ ${ }^{2}$ Laboratoire de Biologie Marine (CP 160/15), Université Libre de Bruxelles, 1050 Brussels, Belgium
}

\begin{abstract}
Understanding the factors that determine the distribution of taxa at various spatial scales is a crucial challenge in the context of global climate change. This holds particularly true for polar marine biota that are composed of both highly adapted and vulnerable faunas. We analysed the distribution of 2 Antarctic echinoid species, Sterechinus antarcticus and S. neumayeri, at the scale of the entire Southern Ocean using 2 niche modelling procedures. The performance of distribution models was tested with regard to the known ecology of the species. The respective contributions of environmental parameters are discussed along with the putative roles played by biotic interactions and biogeographic processes. Depth was the parameter that contributed most to both distribution models, whereas sea ice coverage and sea surface temperature had significant contributions for $S$. neumayeri only. Suitability maps of the 2 species were mostly similar, with a few notable differences. The Campbell Plateau and Tasmania were predicted as suitable areas for $S$. antarcticus only, while $S$. neumayeri was restricted to the south of the Antarctic Polar Front. However, numerous sampling data attest that $S$. antarcticus is absent from the Campbell Plateau and from Tasmania. Different hypotheses are formulated to explain the mismatch between observed and modelled distribution data. They stress the putative roles played by both oceanographic barriers to dispersal (Antarctic Polar Front), biotic factors (species exclusion patterns) and biogeographic processes (ongoing dispersal).
\end{abstract}

KEY WORDS: Habitat suitability map - Sterechinus - Echinoidea - GARP · Maxent · Southern Ocean

\section{INTRODUCTION}

Understanding what determines the distribution of taxa at various spatial scales is a crucial challenge in the context of global climate change (Botkin et al. 2007). This is of particular importance for endemic species, as these species may be more susceptible to additional environmental stress due to climate change if they are unable to overcome the barriers to their dispersal (Ben Rais Lasram et al. 2010). In this context, an accurate and precise knowledge of both the realized and potential distribution of the species is a prerequisite to assess their latent vulnerability.
Prior to any future predictions, the first step in understanding the distribution of a species is using distribution models that identify factors controlling its current distribution. This can be appraised by using 2 types of distribution models. Niche models identify habitat requirements from the correlation between environmental data and species occurrence data (Phillips et al. 2006, Tsoar et al. 2007), while mechanistic models also consider ecophysiological performances when modelling distribution ranges (Buckley et al. 2010). The comparison between observed occurrence data and modelled, predicted distributions might then help estimate species vul- 
nerability to changing environmental conditions. However, identifying the set of determinant factors that controls species distributions is not straightforward, as it usually includes several covarying physical and chemical parameters, along with biotic and biotic-environment interactions (Guisan \& Zimmermann 2000, Phillips et al. 2006). Moreover, the control of environmental parameters on the distribution of taxa is scale-dependent (Austin \& Van Niel 2011). At regional $(>1 \mathrm{~km})$ and local $(<1 \mathrm{~km})$ scales, biogeographic studies actually analyse patterns of population dispersion within taxa distribution ranges that are influenced by many environmental parameters over short periods of time (Lomolino et al. 2006, Chatfield et al. 2010, Gogina et al. 2010). Large-scale analyses are rare (Cheung et al. 2009, Ready et al. 2010) but essential to understanding wide patterns of species distribution. Large-scale patterns result from the complex interplay between Earth's dynamics and biogeographic processes, namely speciation, extinction and dispersal, that have worked together over long periods of time (Lomolino et al. 2006). At such a large scale, the effect of local ecological conditions may not prove determinant (Anderson \& Martinez-Meyer 2004), whereas the impact of past or ongoing global climate change will appear more clearly. As an example, scenarios of future distributions would forecast the concentration of invasive non-polar species at the poleward tips of continental margins only if distribution models are performed at the ocean basin scale (Cheung et al. 2009). Finally, a number of environmental variables such as temperature can prove important in both regional- and global-scale studies (Cheung et al. 2009). This indicates that large-scale studies make it possible to assess how ecological and historical factors have worked together to determine current biogeographic distributions of taxa.

In the last 2 decades, many procedures have been developed to model species distributions as a function of environmental data (Guisan \& Zimmermann 2000, Elith et al. 2006, Marmion et al. 2009). Modelling species distributions as a linear response to ecological parameters has proved inappropriate, and several methods are now available that integrate the interrelated influences of environmental variables (Chatfield et al. 2010). Biological mechanisms that drive the environmental sensitivity of species are not easily accessible for marine species. Therefore, distribution models based on the ecological niche approach correspond to the best available procedure for marine species. The fundamental niche of a species is a theoretical concept that can be defined as the environmental conditions within which a species can survive and persist indefinitely (Hutchinson 1957). The potential niche corresponds to the projection of the fundamental niche in the actual environment; it covers the area potentially suitable for the species considered. The constraints induced by human impact and biotic interactions (predation, competition or symbiosis), or resulting from Earth's dynamics and biogeographic processes lead to the reduction of the potential niche to the realized niche where the species is actually present (Guisan \& Thuiller 2005, Phillips et al. 2006). Procedures of ecological niche modelling aim to identify environmental conditions that are suitable for a species or a community (Guisan \& Thuiller 2005), as an approximation of the fundamental niche (Phillips et al. 2006).

The Southern Ocean shows a rich and diversified marine fauna, despite harsh environmental conditions (e.g. negative water temperatures, ice disturbance in benthic habitats). Its marine life is distinguished from that of other regions by peculiar life strategies (e.g. high rate of brooders over broadcasters) and unique physiological features (e.g. adaptations to very cold water temperature; Poulin et al. 2002). Specific adaptations observed in Antarctic marine biota also reveal their potential vulnerability to environmental change (Pörtner 2006) in view of global warming (Dierssen et al. 2002, Quayle et al. 2002). Many species have evolved adaptations to the cold over a very long period of time and are unable to cope with current rates of global warming or compete with new encroaching species, further restricting their distributions to just the coldest Antarctic areas (e.g. the Weddell and Ross Seas). Deep-sea environments could provide potential refuges for these species, if the candidate species are eurybathic. Therefore, the Southern Ocean provides a promising framework to explore the potential distribution range of endemic species.

Most recent studies investigating the distribution of marine invertebrates and fish have been carried out at regional or local scales, studying space-limited inshore areas (MacLeod et al. 2008). Most have stressed the importance of few environmental parameters such as water depth, salinity and sediment characteristics (Chatfield et al. 2010, Gogina et al. 2010). This also holds true for the Antarctic marine fauna, which has been frequently studied at local and regional scales (see Griffiths et al. 2009 for a review). The Antarctic echinoid diversity is characterized by a high level (ca. $70 \%$ of species) of endemism (David et al. 2005b), and species distribu- 
tions are usually considered to be mainly controlled by depth and sediment characteristics (Brey \& Gutt 1991, Jacob et al. 2003, David et al. 2005b). Primary production combined with other parameters of sea water (e.g. temperature, sea ice coverage, salinity, oxygen and nitrate concentration) may also be important (Thrush et al. 2006, Saiz et al. 2008). In the present work, 2 modelling procedures based on presence-only data, Maxent (Phillips et al. 2006) and GARP (Stockwell \& Peters 1999) were used to model the distribution of echinoid species at the scale of the entire Southern Ocean. We focused on 2 species of the genus Sterechinus that differ in their distribution range: $S$. neumayeri is mostly restricted to the shallows of the Antarctic continental shelf, while $S$. antarcticus is distributed in deep waters of the Antarctic continental shelf and extends its range north as far as $35^{\circ} \mathrm{S}$. The ecology and distribution of the 2 species have been studied extensively (Brey \& Gutt 1991, Jacob et al. 2003, David et al. 2005b), allowing the identification and selection of relevant environmental predictors of their distribution.

Our work aimed to generate a robust and ecological meaningful distribution model at the scale of the Southern Ocean using the most efficient procedure. Good model performance and the identification of environmental parameters driving large-scale distribution patterns should help identify the predicted distribution of species and estimate their potential vulnerability to large-scale environmental changes. The comparison of observed and modelled distribution data should emphasize the roles played by environmental factors included in the model on the one hand, and the suspected biotic interactions and biogeographic processes that have influenced the distribution of Sterechinus species on the other hand.

\section{MATERIALS AND METHODS}

\section{Study area}

The study covers a vast area extending between latitudes 45 and $\sim 70^{\circ} \mathrm{S}$, which is the limit of the Antarctic continent. This area comprises the whole Southern Ocean, including the Antarctic continental shelf and Sub-Antarctic islands, as well as the adjacent areas represented by the southern tips of South America and New Zealand (Fig. 1). This large-scale study encompasses contrasted oceanographic areas and depth ranges, going from true polar to cold-temperate conditions and from shallow to deep-sea environments.

\section{Material and data collection}

Of the 30 echinoid genera recorded in the Southern Ocean (David et al. 2005b), the genus Sterechinus appears as a good candidate to undertake large-scale distribution modelling. It shows a wide distribution area all around Antarctica, over the Antarctic continental shelf, from the shoreline (few metres deep) to the deep slope (2000 m deep), in the Southern Ocean and along the coasts of southern South America (David et al. 2005a). Sterechinus has been among the most frequently collected and commonly studied echinoid genera in the Southern Ocean, and many data regarding its distribution range and ecology are now available (Brey \& Gutt 1991, Barnes \& Brockington 2003, David et al. 2005a,b, Brandt et al. 2007).

Five nominal species were assigned to the genus Sterechinus in the Southern ocean: S. antarcticus Koehler, 1901, S. agassizi Mortensen, 1910, S. diadema (Studer, 1876), S. neumayeri (Meissner, 1900) and $S$. dentifer Koehler, 1926. The 3 species $S$. diadema, S. agassizi and $S$. antarcticus cannot be either morphologically or genetically differentiated (David et al. 2005b, Diaz et al. 2011); thus identification has usually relied on the respective geographic origin: the Kerguelen archipelago (S. diadema), South America ( $S$. agassizi) and Sub-Antarctic and Antarctic areas (S. antarcticus). In the present analysis, they are all referred to as $S$. antarcticus. Data regarding the deep-sea $S$. dentifer are too sparse and could not be analysed. Consequently, only $S$. antarcticus (including $S$. diadema and $S$. agassizi) and $S$. neumayeri were considered, as these 2 species are genetically (Diaz et al. 2011) and morphologically differentiated (Brey \& Gutt 1991, David et al. 2005b). S. antarcticus is mostly a bathyal species (200-1000 m), while $S$. neumayeri is shallower and quite strictly confined to the continental shelf.

Distribution data were taken from the pre-existing Antarctic echinoid database (David et al. 2005a) that integrates most data of the cruises led in Antarctica before 2003. These data were updated by including new reports from recent cruises that have been carried out in Antarctica since 2003, data from specimens housed in museum collections and from recent literature (Table 1). A total of 573 different occurrence data were obtained for the analysis: 332 for $S$. antarcticus and 241 for $S$. neumayeri (Fig. 1).

Environmental variables were selected according to their coverage completeness and large-scale relevance for the entire Southern Ocean, as well as to their known ecological significance to Sterechinus species. Ten variables were retained that specify 


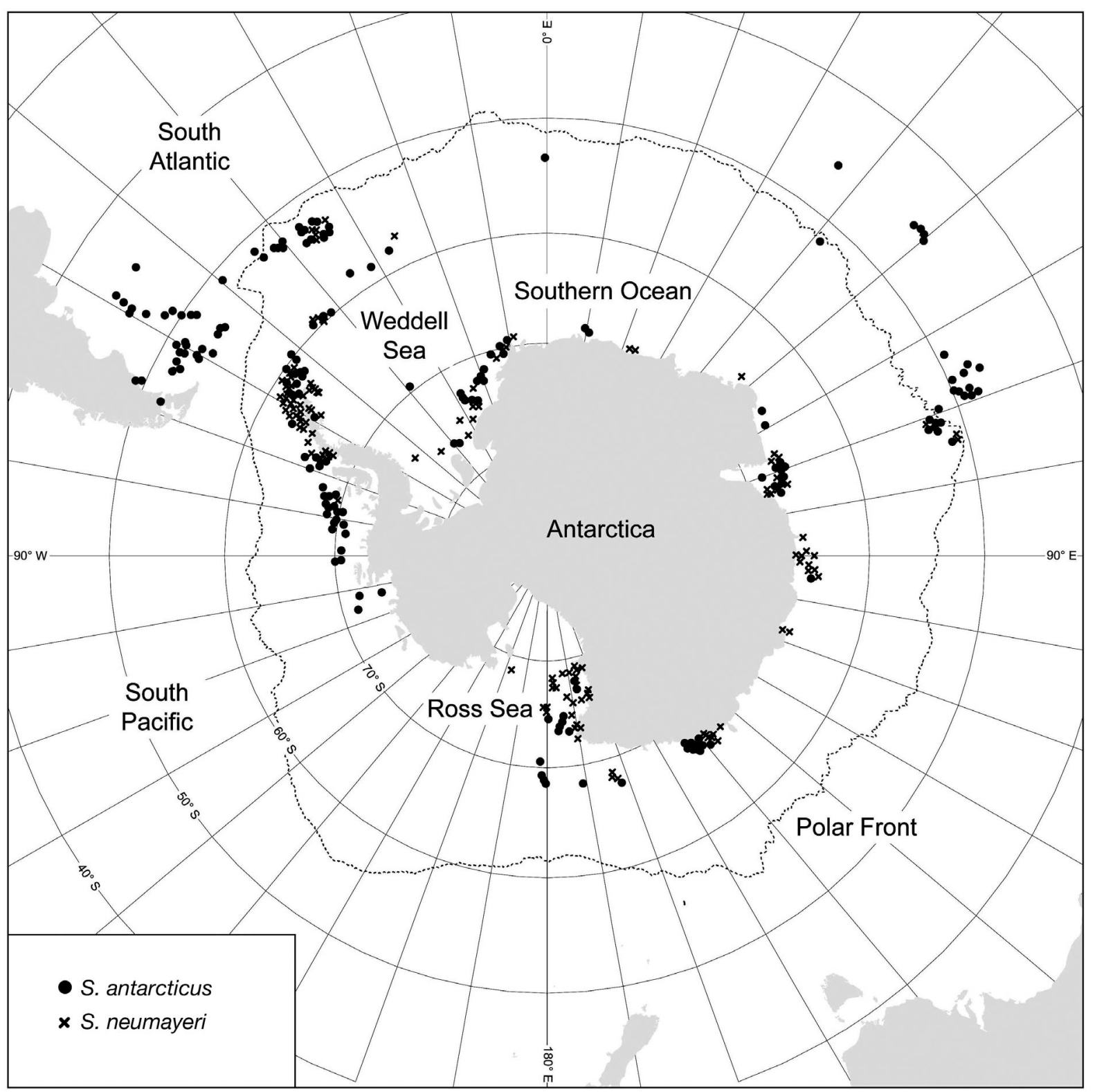

Fig. 1. Sterechinus antarcticus and S. neumayeri. Observed distribution data

physical and chemical characteristics of the seafloor and sea water (Table 2). The majority of the selected variables have direct influence, or correspond to potential resources for the echinoids (according to the classification proposed by Guisan \& Zimmermann 2000). The first 8 variables correspond to continuous data. The 2 latter variables are sediment data that were reviewed according to recent investigations (Diekmann 2007). The first of these variables was categorized into 4 classes according to grain size (clay, silt, sand/gravels and undifferentiated volcanic deposits) and the second into 3 classes that account for the biogenic component $(<60 \%$ biogenic content, $>60 \%$ calcareous biogenic content and $>60 \%$ of siliceous biogenic content). The value and significance of inter-correlations between variables were checked for, as strong correlation values between variables might hamper the reliability of ecological interpretations (Phillips et al. 2006). The Spearman determination coefficient $\left(R_{S}\right)$ computed for pairwise comparisons between the selected variables never surpassed 0.8 with $\mathrm{p}<0.001$. All selected variables were then formatted to fit (1) the World Geodetic System $1984,(2)$ the 45 to $90^{\circ} \mathrm{S}$ latitude and $180^{\circ} \mathrm{E}$ to 
Table 1. Sterechinus antarcticus ( $S$. a.) and $S$. neumayeri $(S, n$.). Sources and number of occurrence data for both species south of latitude $45^{\circ} \mathrm{S}$

\begin{tabular}{|rrl|}
\hline S. a. & S. $n$. & Source \\
\hline 6 & 16 & Australian Museum, Sydney (AUS) \\
31 & 20 & British Antarctic Survey, Cambridge (UK) \\
0 & 4 & $\begin{array}{l}\text { Deheyn et al. (2005), Chiantore et al. (2006), } \\
\text { Gutt et al. (2007) }\end{array}$ \\
52 & 16 & Universität Hamburg, Hamburg (GER) \\
19 & 12 & Melbourne Museum, Melbourne (AUS) \\
7 & 12 & Museo Argentino de Ciencias Naturales, \\
& & Buenos Aires (ARG) \\
28 & 24 & National Institute of Water and Atmospheric \\
& & researches, Wellington (NZ) \\
111 & 100 & Antarctic echinoid database (David et al. 2005a) \\
34 & 11 & Université de Bourgogne, Dijon (FR); Muséum \\
& & National d'Histoire Naturelle, Paris (FR) \\
44 & 25 & Universidad de Malaga, Malaga (SP) \\
& & \\
\end{tabular}

ous and categorical variables, whereas GARP can only process continuous data (Stockwell \& Peters 1999). However, to check for the reliability and reproducibility of the computed niche models, regardless of the modelling method used, outputs of Maxent and GARP procedures were compared using Sterechinus occurrence data and based on the 8 continuous variables of our data set.

\section{Maximum entropy modelling (Maxent)}

Although most recently developed, the Maxent procedure has proved efficient in generating potential species distributions (Elith et al. 2006, 2011) and has been used in many ecological studies on a wide range of organisms (e.g. O'Hara 2008, Tittensor et al. 2009). Max-

$180^{\circ} \mathrm{W}$ longitude geographical template and (3) the $0.5^{\circ} \times 0.5^{\circ}$ cell size using the software ArcGIS 9.3 (www.esri.com).

\section{Data analyses}

Species distribution data gathered during oceanographic cruises or collected from museum collections usually correspond to presence-only data, as true absence data are usually not verifiable. In wide oceanic areas, benthic faunas are usually known through incomplete and uneven sampling, carried out at few locations so that a number of species that are hard to estimate might be missed. The absence of species records could thus either result from a true absence or from sampling incompleteness. This holds particularly true in the Southern Ocean, where sampling is always a challenge and where remote parts still remain under-sampled (Saiz et al. 2008), while other areas like shallow waters off the Antarctic Peninsula have a long history of investigation.

Many methods have been developed for ecological niche modelling (see Guisan \& Zimmermann 2000 for a review) and are still debated (Elith et al. 2006, Marmion et al. 2009). Among many others (e.g. see Tsoar et al. 2007), 2 methods have been used for the last decade to analyse presence-only data: the Genetic Algorithm Rule-set Production (software Desktop GARP - Stockwell \& Peters 1999) and the Maximum Entropy modelling (software Maxent - Phillips et al. 2006). Elith et al. (2011) highlighted the performance of the Maxent procedure, which does not require data normality and can process both continuent has been developed for predicting species distributions from incomplete presence-only information (Phillips et al. 2006). It aims to assess a potential distribution by estimating the maximum entropy probability distribution that is constrained by incomplete information (this information derives from the environmental data associated with presence-only data). The model converges toward a non-random probability distribution (the maximum entropy probability distribution) and yields maps of habitat suitability (Phillips et al. 2006). The software Maxent v.3.3.2 (http://www.cs.princeton.edu/ schapire/maxent/) was run using the 'auto features' mode and default parameters, except for the maximum iteration value (set to 2000). The robustness of the model was evaluated using a '10-fold-cross-validation' procedure and was tested as the ability to predict a 'test subsample' from a 'training subsample'. The performance of the model was estimated using the Area Under the Curve (AUC), by reference to the Receiver Operating Characteristics (ROC) curve, where a value of 1 represents the best possible fit and a value of 0.5 corresponds to a random model (Hosmer \& Lemeshow 2000).

For each species distribution model, results were averaged over the 10 runs of the cross-validation procedure. The averaged results consist of the estimated contributions of each environmental variable to the model along with a suitability map. A probability of presence (varying from 0 to 1 ) is associated with each cell of the map, expressing the local suitability of conditions for each species. From this continuous suitability map, a second threshold map is derived to better visualize the contrasted areas of species potential distributions. Two threshold values were applied. (1) The 
Table 2. Sources, value ranges and short description of the environmental variables selected for the analysis

\begin{tabular}{|c|c|c|c|}
\hline $\begin{array}{l}\text { Environmental } \\
\text { variables }\end{array}$ & $\begin{array}{l}\text { Value } \\
\text { ranges }\end{array}$ & Sources & Processing notes \\
\hline Depth & 0 to $7958 \mathrm{~m}$ & ESRI ${ }^{\circledR} 2005$ & $\begin{array}{l}\text { Global Digital Elevation Model (ETOPO 2) data set } \\
\text { with } 2 \text { min resolution grid. Pixels above sea level set } \\
\text { to "No Data". Data interpolated from original resolution } \\
\text { to } 0.5^{\circ} \text { grid using "Spline with barrier" interpolation } \\
\text { (ArcGIS procedure). }\end{array}$ \\
\hline Slope & 0 to $5.69^{\circ}$ & $\mathrm{ESRI}^{\circledR} 2005$ & $\begin{array}{l}\text { Calculated with ArcGIS Spatial Analyst } \\
\text { (ArcGIS procedure). }\end{array}$ \\
\hline $\begin{array}{l}\text { Sea ice } \\
\text { coverage }\end{array}$ & 0 to $100 \%$ & $\begin{array}{l}\text { Spreen et al. (2008) } \\
\text { http://www.iup.uni- } \\
\text { bremen.de:8084/ } \\
\text { amsredata/asi_daygrid__ } \\
\text { swath/11a/s6250/ }\end{array}$ & $\begin{array}{l}\text { Derived from AMSR-E satellite estimates of daily sea ice } \\
\text { concentration at } 6.25 \mathrm{~km} \text { resolution. Concentration data } \\
\text { from } 1 \text { January } 2003 \text { to } 31 \text { December } 2009 \text { used. } \\
\text { The fraction of time each pixel was covered by sea ice } \\
\text { of at least } 85 \% \text { concentration was calculated for each } \\
\text { pixel in the original (polar stereographic) grid. Data } \\
\text { interpolated from original resolution to } 0.5^{\circ} \text { grid using } \\
\text { "Spline with barrier" interpolation (ArcGIS procedure). }\end{array}$ \\
\hline $\begin{array}{l}\text { Sea surface } \\
\text { temperature } \\
\text { (summer) }\end{array}$ & -1.83 to $15.77^{\circ} \mathrm{C}$ & $\begin{array}{l}\text { Feldman \& McClain (2010) } \\
\text { http://oceancolor.gsfc. } \\
\text { nasa.gov/ }\end{array}$ & $\begin{array}{l}\text { Climatology spans the } 2002 / 03 \text { to } 2009 / 10 \text { austral } \\
\text { summer seasons. Data interpolated from original } \\
\text { resolution to } 0.5^{\circ} \text { grid using "Spline with barrier" inter- } \\
\text { polation (ArcGIS procedure). }\end{array}$ \\
\hline $\begin{array}{l}\text { Seafloor } \\
\text { temperature }\end{array}$ & -2.26 to $9.59^{\circ} \mathrm{C}$ & Clarke et al. (2009) & $\begin{array}{l}\text { Data interpolated from original resolution to } 0.5^{\circ} \text { grid } \\
\text { using "Spline with barrier" interpolation (ArcGIS } \\
\text { procedure). }\end{array}$ \\
\hline Seafloor salinity & 32.21 to 34.89 PSS & $\begin{array}{l}\text { National Oceanographic } \\
\text { Data Center (NODC) } \\
\text { www.nodc.noaa.gov/OC5/ } \\
\text { WOA09/pr_woa09.html }\end{array}$ & $\begin{array}{l}\text { Data interpolated from original resolution to } 0.5^{\circ} \text { grid } \\
\text { using "Spline with barrier" interpolation (ArcGIS } \\
\text { procedure). }\end{array}$ \\
\hline $\begin{array}{l}\text { Sea surface } \\
\text { nitrogen oxide } \\
\text { concentration } \\
\text { (summer) }\end{array}$ & $\begin{array}{l}0.09 \text { to } 34.85 \\
\mu \mathrm{mol} 1^{-1}\end{array}$ & NODC & $\begin{array}{l}\text { Data interpolated from original resolution to } 0.5^{\circ} \text { grid } \\
\text { using "Spline with barrier" interpolation } \\
\text { (ArcGIS procedure). }\end{array}$ \\
\hline $\begin{array}{l}\text { Sea surface } \\
\text { chlorophyll a } \\
\text { concentration }\end{array}$ & 0 to $16.79 \mathrm{mg} \mathrm{m}^{-3}$ & $\begin{array}{l}\text { Feldman \& McClain (2010) } \\
\text { http://oceancolor.gsfc. } \\
\text { nasa.gov/ }\end{array}$ & $\begin{array}{l}\text { Climatology spans the } 2002 / 03 \text { to } 2009 / 10 \text { austral } \\
\text { summer seasons. Data interpolated from original } \\
\text { resolution to } 0.5^{\circ} \text { grid using "Spline with barrier" } \\
\text { interpolation (ArcGIS procedure). }\end{array}$ \\
\hline Granulometry & $\begin{array}{l}\text { Clay, silt, sand } \\
\text { or gravel, } \\
\text { volcanic deposits }\end{array}$ & McCoy (1991) & $\begin{array}{l}\text { Derived from sediment types. Data interpolated from } \\
\text { original resolution to } 0.5^{\circ} \text { grid (ArcGIS procedure). }\end{array}$ \\
\hline $\begin{array}{l}\text { Biogenic } \\
\text { component in } \\
\text { sediment }\end{array}$ & $\begin{array}{l}\text { Azooic, calca- } \\
\text { reous ooze, } \\
\text { biosiliceous ooze }\end{array}$ & McCoy (1991) & $\begin{array}{l}\text { Derived from sediment types. Data interpolated from } \\
\text { original resolution to } 0.5^{\circ} \text { grid (ArcGIS procedure). }\end{array}$ \\
\hline
\end{tabular}

first threshold defines the area referred to as the 'suitable area' and encompasses all pixels for which probability is over the minimal probability value assigned to a true presence $(100 \%$ of true presences are included in this first area). (2) The second one defines the area referred to as the 'highly suitable area' and corresponds to a threshold that excludes the $5 \%$ of the true presences that show the lowest probability values (95\% of true presences are still included in this second area along with the highest probability values).

\section{Genetic Algorithm Rule-set Production (GARP)}

Like Maxent, GARP can be run with presence-only data to predict species potential distributions. Basically, GARP uses rule-sets of logic inferences, selected by means of a genetic algorithm to best predict the species distribution (see Stockwell \& Peters 1999, Peterson et al. 2007 for details). It produces maps of binary predictions. We performed the analysis using the 8 continuous environmental variables and the 
Desktop GARP software v.1.1.6 (www.nhm.ku.edu/ desktopgarp/). Presence-only data were randomly split into training and test subsamples (respectively 75 and $25 \%$ of the total data set) to test the reproducibility and the robustness of the model. One hundred maps were produced using the 'best-subset model selection' procedure (Stockwell \& Peters 1999). This procedure computes maps with $0 \%$ omission value (all pixels with real presence are included in the potential distribution), among which we extracted 2 sets of 10 maps according to their commission value (extension of the predicted area). The first set includes maps whose commissions are the closest to the median commission value (classical procedure described for GARP). In order to compare results from GARP to those from Maxent, the second set comprises maps whose commissions are the closest to the value from Maxent map. For each set, the 10 maps of binary predictions were summed up to generate a 'total' map with prediction values ranging from 0 to 10 for each pixel of the map. To assess the respective contribution of each environmental variable, the procedure described by Peterson et al. (2003) was followed.

\section{RESULTS}

\section{Model performance}

As a preliminary approach, a non-parametric multivariate analysis of variance (MANOVA) was performed using the software PAST v.1.93 (Hammer et al. 2001) to test for the significance of the selected variables to species distribution (as assessed by pixel occurrence and absence data for the entire Southern Ocean). Results were highly significant for both species (Sterechinus antarcticus: $F=30.53, \mathrm{p}<0.0001$; $S$. neumayeri: $F=10.75$, $p=0.0019$ ) using the Euclidean distance and a 10000 replicate permutation test. This shows that the 10 selected variables are correlated at least in part to the distribution of the 2 Sterechinus species and can be used for modelling and estimating their fundamental ecological niches.

Three distribution models were computed for Sterechinus antarcticus and $S$. neumayeri, respectively, using the 2 procedures, GARP (2 outputs using the median and 'best fit' commission values) and Maxent, based on presence-only data and on the 8 continuous environmental variables of the total data set (Fig. 2). Both procedures gave similar results, though with better AUC values for the Maxent $(0.97$ and 0.98 for $S$. antarcticus and $S$. neumayeri, respec- tively) than for the GARP procedure (AUC values for the median and 'best fit' commission values were respectively 0.85 and 0.89 for $S$. antarcticus, 0.91 and 0.87 for $S$. neumayeri). Prediction maps showed similar 'suitable areas'. The 'best fit' GARP (Fig. 2C,D) outputs are very close to the Maxent ones (Fig. 2E,F), although the suitable area computed for $S$. neumayeri is more extended with GARP (Fig. 2D) than with Maxent (Fig. 2F). GARP maps based on the median commission value (Fig. 2A,B) also show more extended suitable areas as compared to Maxent maps (Fig. 2E,F), but patterns do not drastically differ between the 2 models. Suitable areas are either dilated or contracted depending on the model used but the shapes of those areas are not drastically different (the difference is a matter of degree rather than of nature). Finally, both procedures ranked depth as the environmental variable that most contributes to the models. These similar results indicate that basically, the computed prediction models are not only determined by the modelling method used and that they are reliable enough to allow biogeographical interpretations. The Maxent procedure was preferred as it proved efficient and more flexible to process both categorical and continuous variables with data that are not all normally distributed. Therefore, only Maxent results are presented and discussed below.

The AUC values of Maxent distribution models computed for the 2 species showed that these models have a significantly better predictive performance than a random model (Wilcoxon rank-sum test, p < 0.01; Table 3). The AUC values computed for training and test subsamples of each run ranged from 0.924 to 0.97 for Sterechinus antarcticus, and from 0.942 to 0.993 for $S$. neumayeri. Mean values ranged between 0.967 (training data) and 0.952 (test data) for $S$. antarcticus, and between 0.979 (training data) and 0.972 (test data) for $S$. neumayeri, characterizing outstanding models (Hosmer \& Lemeshow 2000).

\section{Species predicted distributions}

The threshold suitability maps computed for the 2 species (Figs. $3 \& 4$ ) show strong similarities (56\% of the 2 maps are similar for highly suitable areas; Fig. A1): highly suitable habitats are mostly predicted all around the Antarctic continent, including the whole Antarctic continental shelf, as well as the Scotia Arc and Sub-Antarctic islands (Bouvet Island, Prince Edward Islands, Crozet Islands, Kerguelen Islands and Heard Island). Highly suitable habitats 

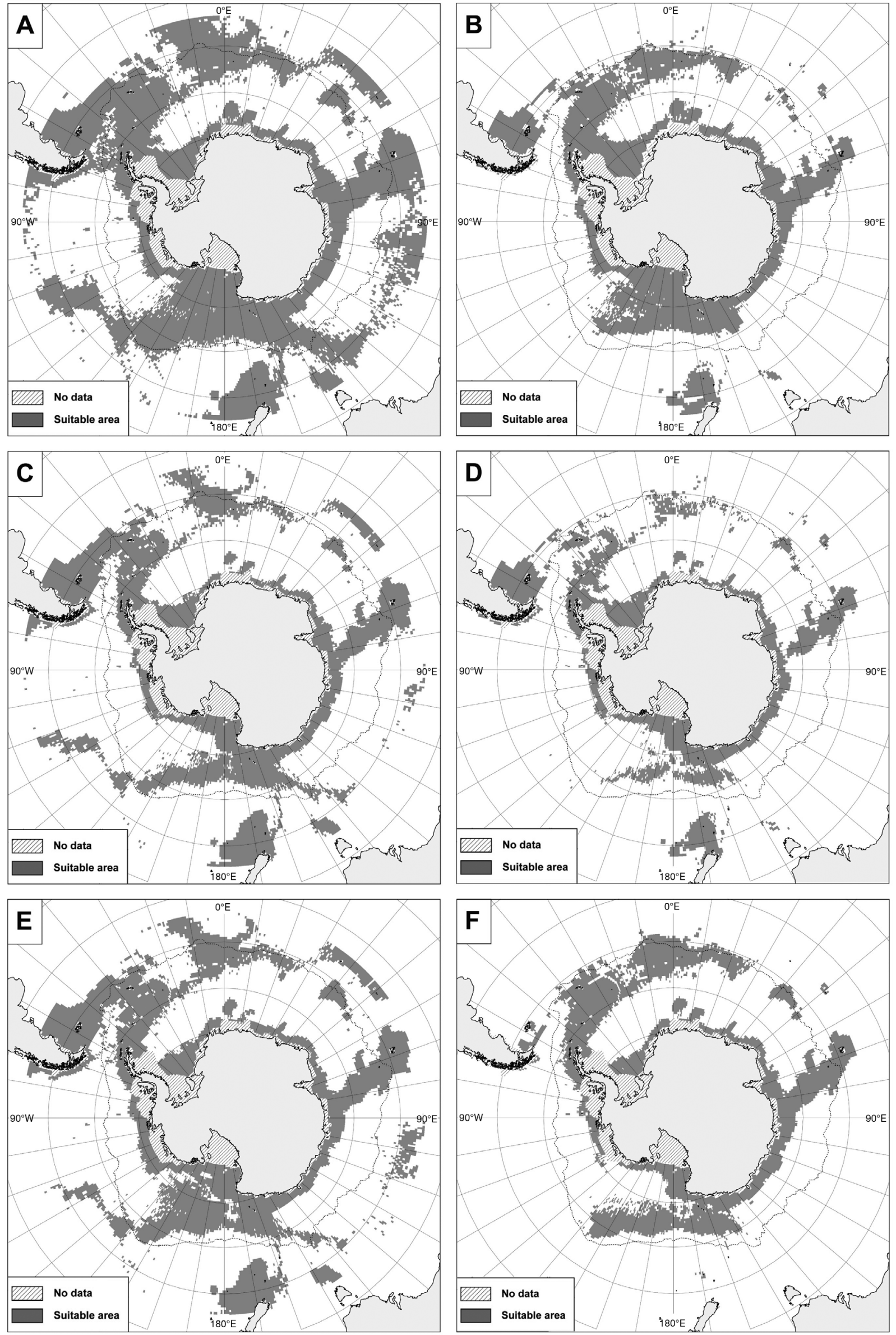
are also predicted northwards as far as the continental shelves of southern Chile and southern Argentina. Suitable habitats include areas from the north of the Ross Sea and between Bouvet Island and the Scotia Arc. Suitable and highly suitable areas extend over a depth range from the shore to $1500 \mathrm{~m}$.

The main discrepancy between the distribution models of the 2 species occurs in the Sub-Antarctic and northernmost areas. Highly suitable areas are predicted for Sterechinus antarcticus south of New Zealand (including the Campbell Plateau) and Tasmania, whereas the predicted distribution of $S$. neumayeri seems to be limited to the Antarctic Polar Front. In southern South America, species distributions are expected over the Argentinean continental shelf and along the Chilean coast, but highly suitable habitats of $S$. neumayeri are restricted to the southernmost tip of Argentina, whereas highly suitable habitats of $S$. antarcticus extend farther northward to $45^{\circ} \mathrm{S}$. In summary, the distribution of $S$. antarcticus is predicted northward as a far as $45^{\circ} \mathrm{S}$, whereas the distribution of $S$. neumayeri is more limited to high latitudes.

\section{Environmental variable contributions}

Previous studies have shown the importance of depth and sediment characteristics to both Sterechinus species distributions (Brey \& Gutt 1991, Jacob et al. 2003, David et al. 2005b). Out of the 10 environmental variables included in the analysis, depth is the variable that most explains the distribution of the 2 species ( 78.1 and $68.7 \%$ of average contribution to $S$. antarcticus and $S$. neumayeri models, respectively; Table 4). For $S$. antarcticus, other environmental variables contributed very little $(<5 \%)$. Regarding $S$. neumayeri, 2 other variables showed a significant contribution: sea ice coverage $(10.4 \%)$ and sea surface temperature $(9.9 \%)$, although these percentages remain well below the value of the depth contribution.

Fig. 2. Sterechinus antarcticus and $S$. neumayeri. Habitat suitability maps for (A, C, E) $S$. antarcticus and (B, D, F) $S$. neumayeri generated by $(\mathrm{A}, \mathrm{B}) \mathrm{GARP}$, using the median commission value (area under the receiver operating curve, AUC $=0.85$ for $S$. antarcticus and 0.91 for $S$. neumayeri), (C, D) GARP, using the Maxent 'best fit' commission value (AUC $=0.89$ for $S$. antarcticus and 0.87 for $S$. neumayeri) and $(\mathrm{E}, \mathrm{F})$ Maxent (AUC $=0.97$ for $S$. antarcticus and 0.98 for $S$. neumayeri). Maps were generated using 8 continuous environmental variables. In the GARP procedure (A-D), 'suitable' areas correspond to pixel values ranging between 6 and 10; they include all occurrence data in the Maxent procedure $(\mathrm{E}, \mathrm{F})$
Table 3. Sterechinus antarcticus and S. neumayeri. Area under the receiver operating curve values computed for each run (for training and test data) with average values for the distribution model of each species. All runs show a significantly better predictive performance than random $(\mathrm{p}<0.01$, Wilcoxon rank-sum test)

\begin{tabular}{|c|c|c|c|c|}
\hline \multirow[t]{2}{*}{ Run } & \multicolumn{2}{|c|}{ Sterechinus antarcticus } & \multicolumn{2}{|c|}{ S. neumayeri } \\
\hline & Training & Test & Training & Test \\
\hline 1 & 0.969 & 0.930 & 0.977 & 0.993 \\
\hline 2 & 0.969 & 0.942 & 0.980 & 0.965 \\
\hline 3 & 0.969 & 0.944 & 0.978 & 0.983 \\
\hline 4 & 0.966 & 0.969 & 0.981 & 0.942 \\
\hline 5 & 0.966 & 0.969 & 0.978 & 0.981 \\
\hline 6 & 0.967 & 0.954 & 0.979 & 0.971 \\
\hline 7 & 0.968 & 0.924 & 0.978 & 0.986 \\
\hline 8 & 0.967 & 0.956 & 0.978 & 0.983 \\
\hline 9 & 0.967 & 0.970 & 0.979 & 0.970 \\
\hline 10 & 0.966 & 0.967 & 0.980 & 0.946 \\
\hline Average & 0.967 & 0.952 & 0.979 & 0.972 \\
\hline
\end{tabular}

\section{DISCUSSION}

\section{Ecological relevance of models}

Depth is the environmental factor that most contributes to delimiting the distribution areas of both Sterechinus species, with sea ice coverage and sea surface temperature partly determining the distribution of $S$. neumayeri as well (Table 4). This is consistent with what we know about the ecological requirements of the 2 species (Brey \& Gutt 1991, Jacob et al. 2003, David et al. 2005b). S. neumayeri inhabits the shallows of the inner continental shelf of Antarctica (mainly between the shore and $500 \mathrm{~m}$ ), and is thus influenced by the environmental parameters that affect the upper water column, such as the seasonal sea ice formation and sea surface temperature. In contrast, these latter parameters have almost no impact on the distribution of $S$. antarcticus, which occurs in deeper areas of the outer parts of continental shelves (mainly between 150 and $750 \mathrm{~m}$, and down to $2000 \mathrm{~m}$ ). The importance of depth as a controlling factor of benthic species distributions has been identified in many marine ecology studies (Brey et al. 1996, O'Hara 2008, Gogina et al. 2010). This has been well established for the genus Sterechinus, which includes 2 species with different depth range distribution (Brey \& Gutt 1991, Jacob et al. 2003, David et al. 2005a). In marine habitats, depth is correlated to many environmental factors such as light intensity, temperature, salinity, predator or competitor occurrence and food supplies (Harris \& Whiteway 2009). The large scale of the analysis means that the 


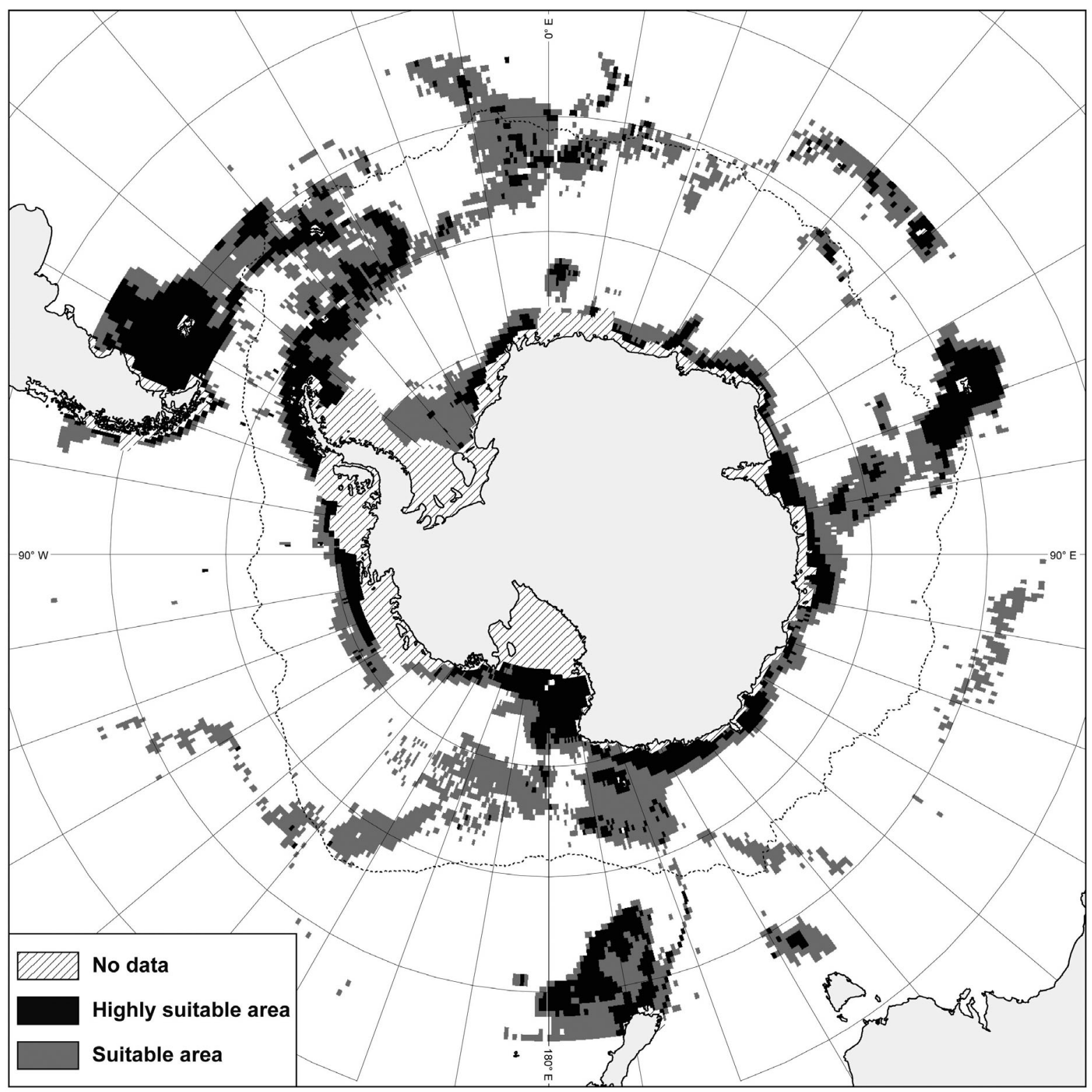

Fig. 3. Sterechinus antarcticus. Habitat suitability map generated using Maxent and including all environmental variables. (1) The 'suitable area' encompasses all pixels for which probability is over the minimal probability value assigned to a true occurrence (100\% of occurrence data are included in this area). (2) The 'highly suitable area' corresponds to a threshold that excludes the $5 \%$ of true occurrences that show the lowest probability values $(95 \%$ of true occurrences are still included in this second area). Hatched areas correspond to areas where data are missing for at least 1 environmental variable

local environmental control on population dispersion is likely to have less influence, while large-scale environmental variations are more likely to explain broad patterns of species distributions. Depth is typically a factor that can control species distributions at local, regional and global scales. The large scale of the present analysis partly explains the predominant contribution of depth to distribution models over other environmental parameters. However, future efforts should concentrate on adding new environmental data and estimating their potential contribution to the modelled habitats. Therefore, depth could also be an indirect estimate, or a proxy for other variables that do have a direct and significant impact on species distributions. However, it has been shown that depth can have a direct impact on marine life, and niche modelling studies in marine areas generally include depth as a full-fledged environmental 


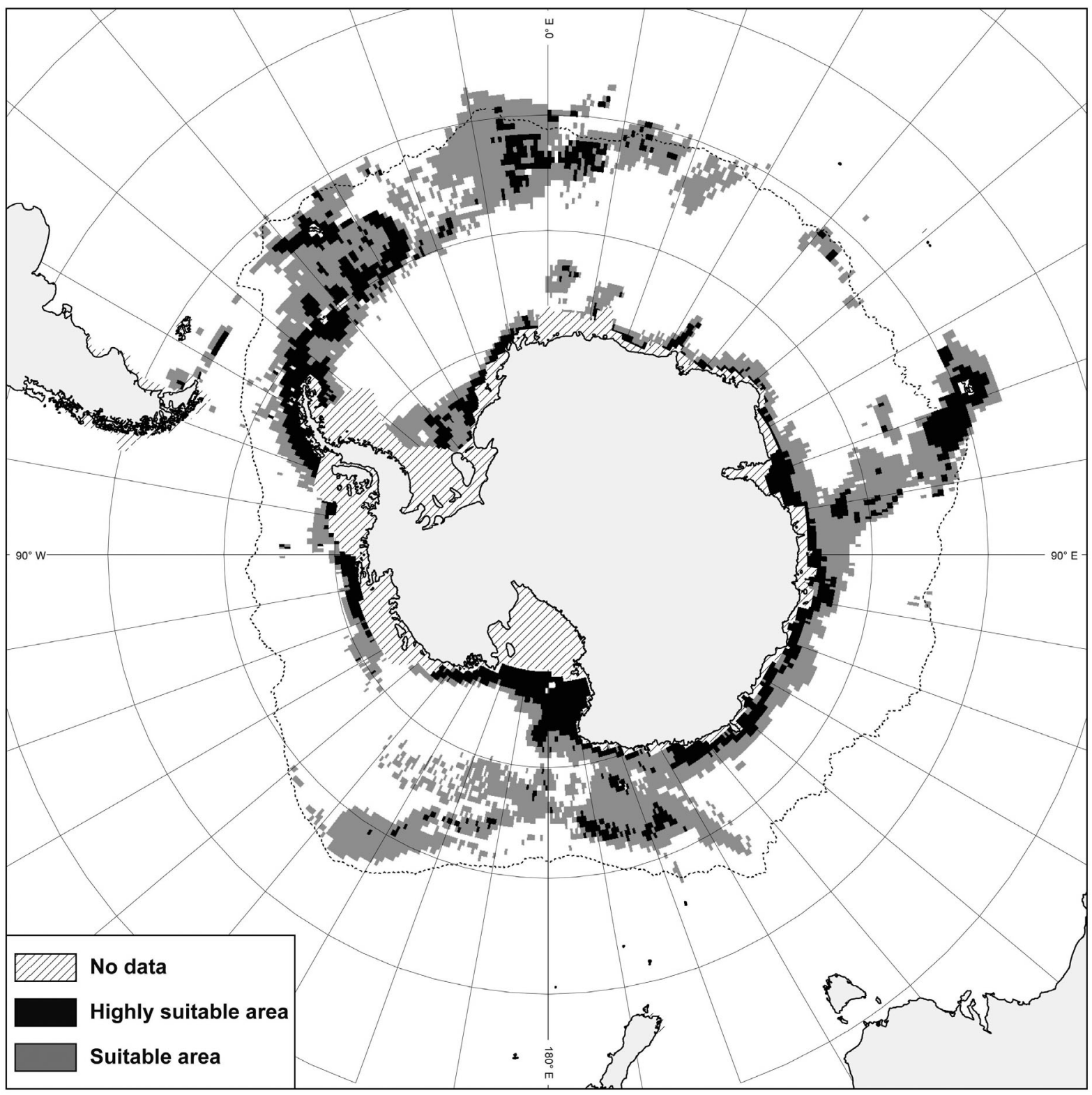

Fig. 4. Sterechinus neumayeri. Habitat suitability map generated using Maxent and including all environmental variables. (1) The 'suitable area' encompasses all pixels for which probability is over the minimal probability value assigned to a true occurrence (100\% of occurrence data are included in this area). (2) The 'highly suitable area' corresponds to a threshold that excludes the $5 \%$ of true occurrences that show the lowest probability values $(95 \%$ of true occurrences are still included in this second area). Hatched areas correspond to areas where data are missing for at least 1 environmental variable

parameter (O'Hara 2008, Gogina et al. 2010). One of the main reasons for this is pressure increase with depth. Tyler et al. (2000) showed that in S. neumayeri, water pressure is a limiting factor for the survival and dispersal of larvae into deep waters, which favours the settlement of the species to shallow water areas.

The 2 Sterechinus species studied here are opportunistic feeders, with differences in the diet being insignificant (Jacob et al. 2003), and are likely to be little impacted by seasonal variation in primary production (De Ridder \& Lawrence 1982, David et al. 2005b). This could partly explain the low contribution of those parameters describing the sediment biogenic component and the water chlorophyll $a$ rate in the distribution models. However, the significance of sea ice coverage and sea surface temperature to the distribution of $S$. neumayeri can be related to the 
Table 4. Sterechinus antarcticus (S. a.) and $S$. neumayeri (S. n.). Average contribution (\%) of each environmental variable for distribution models of each species

\begin{tabular}{|lcc|}
\hline Environmental variable & S. $a$. & S. $n$. \\
\hline Depth & 78.1 & 68.7 \\
Slope & 2.7 & 1.3 \\
Sea ice coverage & 4.3 & 10.4 \\
Sea surface temperature & 2.3 & 9.9 \\
Seafloor temperature & 0.8 & 0.2 \\
Seafloor salinity & 2 & 0.7 \\
Sea surface nitrogen oxide conc. & 3.7 & 0.5 \\
Sea surface chlorophyll a conc. & 2.4 & 2.8 \\
Granulometry & 1.3 & 1.2 \\
Biogenic component in sediment & 2.4 & 4.3 \\
\hline
\end{tabular}

availability of food supplies. Shallow areas of East Antarctica (<15 m depth) are covered with ice for most of the year, a necessary condition for microphyte growth that initiates a trophic web. This food attracts mobile animals such as $S$. neumayeri (Thrush et al. 2006), which might be partly dependent on this source of food. Our results suggest that further studies in functional ecology might consider the ecological implication of sea ice coverage and sea surface temperature in population dynamics of $S$. neumayeri.

\section{Environmental control versus historical contingencies}

Compared to Sterechinus antarcticus, the habitat of $S$. neumayeri is shown to be determined by, or at least related to, environmental parameters other than depth (i.e. sea ice coverage and sea surface temperature), and its modelled distribution range is accordingly less extended. In $S$. neumayeri, the complex interaction between depth and its correlates is well exemplified. Tyler et al. (2000) demonstrated that pressure tolerance of larvae is dependent on water temperature, warmer temperatures tending to increase pressure tolerance of larvae. In a forecasting scenario, a slight warming of bottom waters could therefore promote the larval dispersal and the settlement of $S$. neumayeri in deeper waters and in the most northern parts of the Southern Ocean. In the latter case, climate change may have a direct impact on the distribution of $S$. neumayeri, driving the expansion of its distribution range. Conversely, during the Pleistocene, glacial maxima could have favoured the contraction of its distribution range to the shallow areas of Antarctic and Sub-Antarctic regions.
Biogeographic discrepancies between observed data and modelled distributions are partly inherent to the modelling procedure and conditioned by the incompleteness of environmental data and the scale of the analyses. These biogeographic discrepancies can also result from the essential differences that distinguish between the fundamental and the realized ecological niche. They may indicate the role played both by historical events and by biotic interactions in the present distribution of taxa. Although historical factors (e.g. ongoing dispersal) and biotic interactions (e.g. competition, predation) were not included as parameters in our approach, they can be regarded a posteriori as causal factors to interpret distribution patterns that are not fully explained by physical and chemical parameters. In the present work, the modelled habitats of the 2 Sterechinus species only differed by the secondary contribution of 2 parameters, sea ice coverage and sea surface temperature, as compared to depth, the factor that contributed the most to both species distribution models. Accordingly, the 2 modelled distributions differ in their northward latitudinal range while distribution patterns of both species widely overlap (Figs. $3 \& 4$ ). However, the comparison of occurrence data shows that the observed distributions of the 2 species only overlap over $8.6 \%$ of their total distribution range ( 26 pixels in common over 302 pixels in all). This suggests that the 2 species might partly exclude each other, while environmental requirements do not differ drastically. To test for the origin of the exclusion pattern between the 2 species, a non-parametric MANOVA was performed with PAST using the Euclidean distance and a 10000 replicate permutation test. The exclusion did not rely significantly on environmental differences $(F=0.032 ; \mathrm{p}=0.86)$ and cannot be supported at the scale of the Southern Ocean so far. It is very likely that the exclusion is of biological origin.

The comparison between the modelled and observed distribution of Sterechinus antarcticus also sheds light on factors that were not included in the model. The potential distribution of $S$. antarcticus extends northeastward over the Campbell Plateau where environmental conditions were modelled as suitable to highly suitable for the species (Fig. 3). Moreover, dispersal by means of the Antarctic Circumpolar Current would make the colonization of the plateau possible for a species that originated in the Southern Ocean (O'Hara 1998). However, no $S$. antarcticus has ever been sampled south of New Zealand, despite the many oceanographic campaigns led in the region. Hypotheses can then be 
proposed to explain this situation that invoke either (1) oceanographic barriers, (2) biotic interactions or (3) historical contingencies.

(1) The Antarctic Polar Front (APF) is classically regarded as a biogeographic, physiographical barrier to dispersal, having isolated the Southern Ocean from northern warmer water masses since Drake Passage opened (Scher \& Martin 2006, Clarke et al. 2007). Regarding Sterechinus, the APF barrier seems to prevent $S$. neumayeri from expanding its range to the north as its potential distribution was modelled beyond the APF over the south of the Argentinean Plateau (Fig. 4) whereas occurrence data do not extend across the APF (Fig. 1). In contrast, $S$. antarcticus extends beyond the APF over the Argentinean Plateau as far as $35^{\circ} \mathrm{S}$ (Fig. 1) and its range does not seem to be restricted by the APF on the South American side. Conversely, the APF barrier would be particularly influential between the Campbell Plateau and East Antarctica (Bargelloni et al. 2000), where it could prevent the larvae of $S$. antarcticus from dispersing toward the Campbell Plateau. Dispersal of $S$. antarcticus could be possible in the future as the APF barrier is expected to weaken with global warming (Convey et al. 2009).

(2) Biotic interactions may also limit the distribution of Sterechinus antarcticus and its settlement over the Campbell Plateau. Another member of the family Echinidae, Gracilechinus multidentatus, inhabits the Campbell Plateau. G. multidentatus is a close relative to Sterechinus species and occupies similar depth ranges and habitats (McKnight 1968). Interspecific competition between these 2 species may lead to a species exclusion of either the New Zealand species, G. multidentatus or the South American, Sub-Antarctic and Antarctic species, S. antarcticus.

(3) Niche modelling has been criticized for considering ecological niches as being at the equilibrium and for ignoring biogeographic processes such as speciation, adaptation, extinction and dispersal dynamics (Austin \& Van Niel 2011). Herein, we considered these processes as causal factors that may be considered a posteriori to justify possible biogeographic discrepancies between observed and modelled distribution data. In the Southern Ocean, the re-colonization of the Antarctic continental shelf by benthic species after the glacial maxima of the Pleistocene constitutes a recent historical background that must be taken into account when considering the present distribution patterns of taxa, as it is not possible to know whether the process occurred in the past or is ongoing (Brandt et al. 2007). While Sterechinus neumayeri is assumed to have origi- nated on the Antarctic continental shelf by allopatric speciation during the Pliocene, $S$. antarcticus would have originated from Subantarcic waters where it would have dispersed to the Antarctic continental shelf during glacial optima of the Pleistocene (Diaz et al. 2011). This dispersal process could be ongoing and may explain the absence of $S$. antarcticus on the Campbell Plateau. Originating from Sub-Antarctic areas on the South American side, the species would not have reached the Campbell Plateau as yet.

\section{CONCLUSION}

The present work constitutes a first attempt to generate a niche-based distribution model at the scale of the Southern Ocean. Distribution models of Sterechinus antarcticus and S. neumayeri were generated using 2 methods, GARP and Maxent. The latter was preferred for providing better predictive performance, as assessed by the high AUC values of distribution models. However, both procedures provided similar predictive distribution maps, therefore suggesting the reproducibility of the models. The modelled ecological niches are consistent with the known ecology of the 2 Sterechinus species, the identification of those environmental parameters that contribute most to large-scale distribution patterns showing good agreement with the observed and modelled distribution ranges. Hence, the endemism of $S$. neumayeri to the Antarctic continental shelf can be explained by depth, sea ice coverage and sea surface temperature, while depth is the only significant factor found to control the widespread distribution of $S$. antarcticus. The difference between the 2 modelled potential distributions could be interpreted to assess the respective potential vulnerability of the 2 species to large-scale environmental changes of the past and to those expected in the future.

Regardless of the modelling procedure adopted, the differences between observed and modelled distribution data emphasized the respective roles played by those environmental factors included in the model (depth, sea ice coverage and sea surface temperature), and by putative biotic and biogeographic processes. Hence, species exclusion patterns and ongoing dispersal processes were proposed as likely factors that could determine the mismatch between the fundamental and the realized ecological niches. Such a modelling approach is recommended to be applied to other taxa of the Southern Ocean. The identification of recurrent distribution patterns with recurrent discrepancies between modelled and 
observed distribution data in phylogenetically distant taxa may provide insight into the impact of Antarctic biogeographic history on present distribution patterns and might help assess species resilience to large-scale environmental changes.

Acknowledgements. This paper is a contribution of the BIOME team of UMR CNRS 6282 Biogéosciences. We thank B. Danis, H. Griffiths and B. Raymond for their contribution to the environmental data set, T. Thevenin and F. Tolle for their help with ArcGIS, the Muséum National d'Histoire Naturelle in Paris, the Australian Museum in Sydney, the British Antarctic Survey in Cambridge, the Universität Hamburg, the Melbourne Museum, the Museo Argentino de Ciencas Naturales in Buenos Aires, the National Institute of Water and Atmospheric Researches in Wellington and the Universidad de Malaga for access to collections. Funding sources were from CAML/TOTAL, ANR ANTFLOCKS (no. 07-BLAN-0213-01), ECOS project (no. C06B02) and BIANZO I and II projects (Belgian Science Policy). We thank our reviewers for improving the quality of the manuscript.

\section{LITERATURE CITED}

Anderson RP, Martinez-Meyer E (2004) Modeling species' geographic distributions for preliminary conservation assessments: an implementation with the spiny pocket mice (Heteromys) of Ecuador. Biol Conserv 116:167-179

> Austin MP, Van Niel KP (2011) Improving species distribution models for climate change studies: variable selection and scale. J Biogeogr 38:1-8

Bargelloni L, Zane L, Derome N, Lecointre G, Patarnello T (2000) Molecular zoogeography of Antarctic euphausiids and notothenioids: from species phylogenies to intraspecific patterns of genetic variation. Antarct Sci 12:259-268

Barnes DKA, Brockington S (2003) Zoobenthic biodiversity, biomass and abundance at Adelaide Island, Antarctica. Mar Ecol Prog Ser 249:145-155

Ben Rais Lasram FB, Guilhaumon F, Albouy C, Somot S, Thuillier W, Mouillot D (2010) The Mediterranean Sea as a "cul-de-sac" for endemic fishes facing climate change. Glob Change Biol 16:3233-3245

> Botkin DB, Saxe H, Araùjo MB, Betts R and others (2007) Forecasting the effects of global warming on biodiversity. Bioscience 57:227-236

Brandt A, Gooday AJ, Brandao SN, Brix S and others (2007) First insights into the biodiversity and biogeography of the Southern Ocean deep sea. Nature 447:307-311

Brey T, Gutt J (1991) The genus Sterechinus (Echinodermata, Echinoidea) on the Weddell Sea shelf and slope (Antarctica) - distribution, abundance and biomass. Polar Biol 11:227-232

> Brey T, Dahm C, Gorny M, Klages M, Stiller M, Arntz W (1996) Do Antarctic benthic invertebrates show an extended level of eurybathy? Antarct Sci 8:3-6

Buckley LB, Urban MC, Angilletta MJ, Crozier LG, Rissler LJ, Seras MW (2010) Can mechanism inform species' distribution models? Ecol Lett 13:1041-1054

Chatfield BS, Van Niel KP, Kendrick GA, Harvey ES (2010) Combining environmental gradients to explain and predict the structure of demersal fish distributions. J Biogeogr 37:593-605
Cheung WWL, Lam VWY, Sarmiento JL, Kearney K, Watson R, Pauly D (2009) Projecting global marine biodiversity impacts under climate change scenarios. Fish Fish 10: 235-251

> Chiantore M, Guidetti M, Cavallero M, De Domenico F, Albertelli G, Cattaneo-Vietti R (2006) Sea urchins, sea stars and brittle stars from Terra Nova Bay (Ross Sea, Antarctica). Polar Biol 29:467-475

> Clarke A, Griffiths HJ, Linse K, Barnes DKA, Crame JA (2007) How well do we know the Antarctic marine fauna? A preliminary study of macroecological and biogeographical patterns in Southern gastropod and bivalve molluscs. Divers Distrib 13:620-632

Clarke A, Griffiths HJ, Barnes DKA, Meredith MP, Grant SM (2009) Spatial variation in seabed temperatures in the Southern Ocean: implications for benthic ecology and biogeography. J Geophys Res 114:G03003 doi: 10.1029/2008JG000886

Convey P, Bindschadler R, Di Prisco G, Fahrbach E and others (2009) Antarctic climate change and the environment. Antarct Sci 21:541-563

- David B, Choné T, Festeau A, Mooi R, De Ridder C (2005a) Biodiversity of Antarctic echinoids: a comprehensive and interactive database. Sci Mar 69(Suppl 2):201-203

David B, Choné T, Mooi R, De Ridder C (2005b) Antarctic Echinoidea. Synopses of the Antarctic benthos, Vol 10. Koeltz Scientific Books, Königstein

De Ridder C, Lawrence JM (1982) Food and feeding mechanisms: Echinoidea. In: Jangoux M, Lawrence JM (eds) Echinoderm nutrition. A.A. Balkema, Rotterdam, p 57-115

> Deheyn DD, Gendreau P, Baldwin RJ, Latz MI (2005) Evidence for enhanced bioavailability of trace elements in the marine ecosystem of Deception Island, a volcano in Antarctica. Mar Environ Res 60:1-33

> Diaz A, Féral JP, David B, Saucède T, Poulin E (2011) Evolutionary pathways among shallow and deep-sea echinoids of the genus Sterechinus in the Southern Ocean. Deep-Sea Res II 58:205-211

> Diekmann B (2007) Sedimentary patterns in the late Quaternary Southern Ocean. Deep-Sea Res II 54:2350-2366

Dierssen HM, Smith RC, Vernet M (2002) Glacial meltwater dynamics in coastal waters west of the Antarctic peninsula. Proc Natl Acad Sci USA 99:1790-1795

> Elith J, Graham CH, Anderson RP, Dudik M and others (2006) Novel methods improve prediction of species' distributions from occurrence data. Ecography 29:129-151

> Elith J, Phillips SJ, Hastie T, Dudik M, Chee YE, Yates CJ (2011) A statistical explanation of MaxEnt for ecologists. Divers Distrib 17:43-57

Feldman GC, McClain CR (2010) Ocean Color Web. MODIS Aqua Reprocessing. Available at http://oceancolor.gsfc. nasa.gov/REPROCESSING/Aqua/R1.1/

Gogina M, Glockzin M, Zettler ML (2010) Distribution of benthic macrofaunal communities in the western Baltic Sea with regard to near-bottom environmental parameters. 1. Causal analysis. J Mar Syst 79:112-123

> Griffiths HJ, Barnes DKA, Linse K (2009) Towards a generalized biogeography of the Southern Ocean benthos. J Biogeogr 36:162-177

> Guisan A, Thuiller W (2005) Predicting species distribution: offering more than simple habitat models. Ecol Lett 8: 993-1009

Guisan A, Zimmermann NE (2000) Predictive habitat distribution models in ecology. Ecol Model 135:147-186 
Gutt J, Koubbi P, Eléaume M (2007) Mega-epibenthic diversity off Terre Adélie (Antarctica) in relation to disturbance. Polar Biol 30:1323-1329

Hammer O, Harper DAT, Ryan PD (2001) PAST: paleontological statistics software package for education and data analysis. Palaeontol Electron 4:1-9

> Harris PT, Whiteway T (2009) High seas marine protected areas: benthic environmental conservation priorities from a GIS analysis of global ocean biophysical data. Ocean Coast Manag 52:22-38

Hosmer DWJ, Lemeshow S (2000) Applied logistic regression, 2nd edn., Wiley, New York, NY

Hutchinson GE (1957) Concluding remarks. Cold Spring Harb Symp Quant Biol 22:415-427

Jacob U, Terpstra S, Brey T (2003) High-Antarctic regular sea urchins - the role of depth and feeding in niche separation. Polar Biol 26:99-104

Lomolino MV, Riddle BR, Brown JH (2006) Biogeography, 3rd edn. Sinauer Associates, Sunderland, MA

> MacLeod CD, Mandleberg L, Schweder C, Bannon SM, Pierce GJ (2008) A comparison of approaches for modelling the occurrence of marine animals. Hydrobiologia 612:21-32

Marmion M, Luoto M, Heikkinen RK, Thuiller W (2009) The performance of state-of-the-art modelling techniques depends on geographical distribution of species. Ecol Model 220:3512-3520

McCoy FW (1991) Southern Ocean sediments: circumAntarctic to $30^{\circ} \mathrm{S}$. In: Hayes E (ed) Marine geological and geophysical atlas of the circum-antarctic to $30^{\circ} \mathrm{S}$. Antarct Res Ser 54:37-46

McKnight DG (1968) Additions to the echinoid fauna of New Zealand. NZ J Mar Freshw Res 2:90-110

O'Hara TD (1998) Origin of Macquarie Island echinoderms. Polar Biol 20:143-151

O'Hara TD (2008) Bioregionalisation of the waters around Lord Howe and Norfolk Islands using brittle stars (Echinodermata: Ophiuroidea). Report by Museum Victoria to the Department of Environment, Water, Heritage and the Arts (Australia), Melbourne

Peterson AT, Papes M, Kluza DA (2003) Predicting the potential invasive distribution of four alien plant species in North America. Weed Sci 51:863-868

Peterson AT, Papes M, Eaton M (2007) Transferability and model evaluation in ecological niche modeling: a comparison of GARP and Maxent. Ecography 30: 550-560

Phillips SJ, Anderson RP, Schapire RE (2006) Maximum entropy modeling of species geographic distributions. Ecol Model 190:231-259

Pörtner HO (2006) Climate-dependent evolution of Antarctic ectotherms: an integrative analysis. Deep-Sea Res II 53:1071-1104

Poulin E, Palma AT, Féral JP (2002) Evolutionary versus ecological success in Antarctic benthic invertebrates. Trends Ecol Evol 17:218-222

> Quayle WC, Peck LS, Peat H, Ellis-Evans JC, Harrigan PR (2002) Extreme responses to climate change in Antarctic lakes. Science 295:645-646

Ready J, Kaschner K, South AB, Eastwood PD and others (2010) Predicting the distributions of marine organisms at the global scale. Ecol Model 221:467-478

Saiz JI, Garcia FJ, Manjon-Cabeza ME, Parapar J and others (2008) Community structure and spatial distribution of benthic fauna in the Bellingshausen Sea (West Antarctica). Polar Biol 31:735-743

Scher HD, Martin EE (2006) Timing and climatic consequences of the opening of Drake Passage. Science 312: 428-430

Spreen G, Kaleschke L, Heygster G (2008) Sea ice remote sensing using AMSR-E $89 \mathrm{GHz}$ channels. J Geophys Res 113:C02S03 doi:10.1029/2005JC003384

Stockwell D, Peters D (1999) The GARP modelling system: problems and solution to automated spatial prediction. Int J Geogr Inf Sci 13:143-158

- Thrush S, Dayton P, Cattaneo-Vietti R, Chiantore M and others (2006) Broad-scale factors influencing the biodiversity of coastal benthic communities of the Ross Sea. Deep-Sea Res II 53:959-971

> Tittensor DP, Baco AR, Brewin PE, Clark MR and others (2009) Predicting global habitat suitability for stony corals on seamounts. J Biogeogr 36:1111-1128

> Tsoar A, Allouche O, Steinitz O, Rotem D, Kadmon R (2007) A comparative evaluation of presence-only methods for modelling distribution. Divers Distrib 13:397-405

Tyler PA, Young CM, Clarke A (2000) Temperature and pressure tolerances of embryos and larvae of the Antarctic sea urchin Sterechinus neumayeri (Echinodermata: Echinoidea): potential for deep-sea invasion from high latitudes. Mar Ecol Prog Ser 192:173-180 
Appendix. Additional data on potential distribution of 2 echinoids in the Southern Ocean

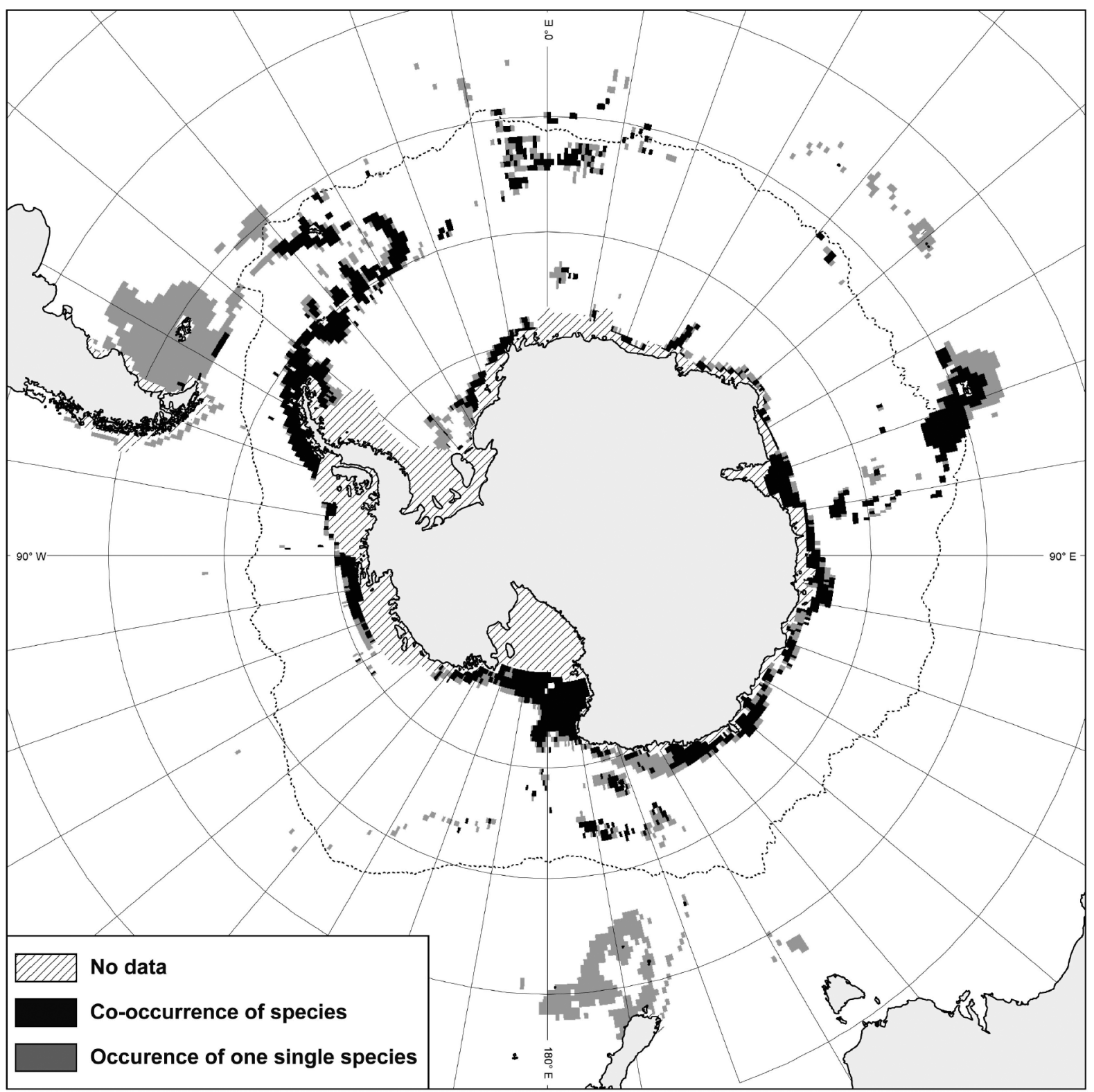

Fig. A1. Potential distribution showing pixels where Sterechinus antarcticus and S. neumayeri occur together and where only 1 species is potentially present

Editorial responsibility: Lisandro Benedetti-Cecchi, Pisa, Italy
Submitted: February 13, 2012; Accepted: May 24, 2012 Proofs received from author(s): August 21, 2012 